Review

\title{
Aflatoxins in Mozambique: a Historical Review
}

\author{
Edgar Cambaza ${ }^{1,2, *}$, Shigenobu Koseki ${ }^{1}$ and Shuso Kawamura ${ }^{1}$ \\ 1 Laboratory of Agricultural and Food Process Engineering, Graduate School of Agriculture, Hokkaido \\ Universiy, Sapporo, Japan; edy@bpe.agr.hokudai.ac.jp \\ 2 Department of Biological Sciences, Faculty of Sciences, Eduardo Mondlane University, Maputo, \\ Mozambique; cecoma@uem.ac.mz \\ * Correspondence: accademus@protonmail.com; Tel.: +81-80-2876-1106
}

\begin{abstract}
In Mozambique, the aflatoxin research started in 1960's and has been carried through apparently unrelated efforts according to opportunities. However, there was a major trend divided in early epidemiological studies and recent agricultural research. Early investigators found strong correlation between aflatoxin contamination and primary liver cancer. Since then, there have been efforts to analyze the extent of contamination, especially in groundnuts and maize. More recent investigation and intervention aimed mostly to reduce the level of contamination enough to allow such commodities to gain acceptance in the international market. The current status of knowledge is still marginal but the increasing involvement of local authorities, academia and international organizations seems promising.
\end{abstract}

Keywords: aflatoxin, history, research, Mozambique

\section{Introduction}

Aflatoxins are undoubtedly the most studied mycotoxins in Mozambique, especially aflatoxin $\mathrm{B}_{1}\left(\mathrm{AFB}_{1}\right)$. This is due to records of local epidemiological association between this toxin and hepatic cancer [1], and export restrictions of contaminated groundnuts and maize [2]. There are reports on fumonisins and other toxins [3,4], but these are very few compared to the information on AFB 1 . Yet, there is still a need for surveys on food safety covering several foods in the entire country.

The paper by Van Rensburg, Cook-Mozaffari, Van Schalkwyk, Van der Watt, Vincent and Purchase [1] on HCC and AFB 1 consumption is certainly the most cited about this toxin in Mozambique and one of the most well-known on the etiology of liver cancer. It was an update of Van Rensburg, et al. [5] and Harington, et al. [6] about cancer in Southern Africa. However, these reports were published over 30 years ago and might be outdated at some extent. Since then, Mozambique has undergone major socio-demographic and politic changes. Also, they only covered a few areas in the south of Mozambique. Since then, there have been updates reflecting new challenges in health sciences and agriculture.

This article presents an overview of the Mozambican aflatoxin research, covering its historical aspects, features, main findings and potential or actual implications for health and society. Such information will be useful for scholars and researchers, students, professionals, trade partners and decision-makers for the country's development.

\section{Research driving forces}

This digest is based on events' interconnections rather than a straight timeline exposing them. The time was also considered and there is a notable distinction between the early and recent eras from a practical perspective to be explored in this document. Yet, there is a rationale behind this distinction. One cannot detach the events from the sociopolitical context because it defines the country's priorities and actions.

The early studies were performed during the pre-democratic Mozambique, mostly taking an epidemiological approach. These are from the colonial era (before 1975) and most of its legacy, even 
during the civil war (until 1992) and the adaptation to the new democratic regime (roughly the entire 1990's). South African gold miners initially supported these studies as an effort to know about the health of their potential and actual workers and their families. It explains why most studies were performed in the Mozambican southern provinces. The post-independence government of Mozambique did not support the apartheid and it certainly affected the collaborative works between both countries. Any South African scholar or intellectual circulating in Mozambican territory would be seen as suspicious at least. In 1994, when the African National Congress rose to power, the regime changed and it affected the industry policies [7], certainly leading it to new directions. Furthermore, most people leading this line of research must have aged and retired. This line of research still exists but it is not as active without the initial incentive.

The most recent studies can be regarded as the ones from this millennium, more focused on agriculture. The entire international landscape was influenced by the Millennium Development Goals (MDG) set by the United Nations in 2000 to support developing countries [8]. The goals encouraged the country to design the National Plan to Reduce Poverty [9]. The first MDG was to eradicate extreme poverty and hunger. It clearly encouraged efforts from food supply chains, especially the primary sector (agriculture and fishery). Fields such as food safety, nutrition, quality gained an unprecedented attention, though food security was the major focus. Some millennium goals were towards health but infectious diseases and anemia have more priority than cancer in Mozambique. The deadline for the goals was 2015 and there are now the Sustainable Development Goals [10] but the direction seems to be the same.

\section{Overview in different commodities}

The Figure 1 shows a meta-analysis on the variation in products and how many samples were analyzed and the results published in Mozambique since the beginning. Some studies were excluded for the lack of complete data or consistent information but the most relevant were included.

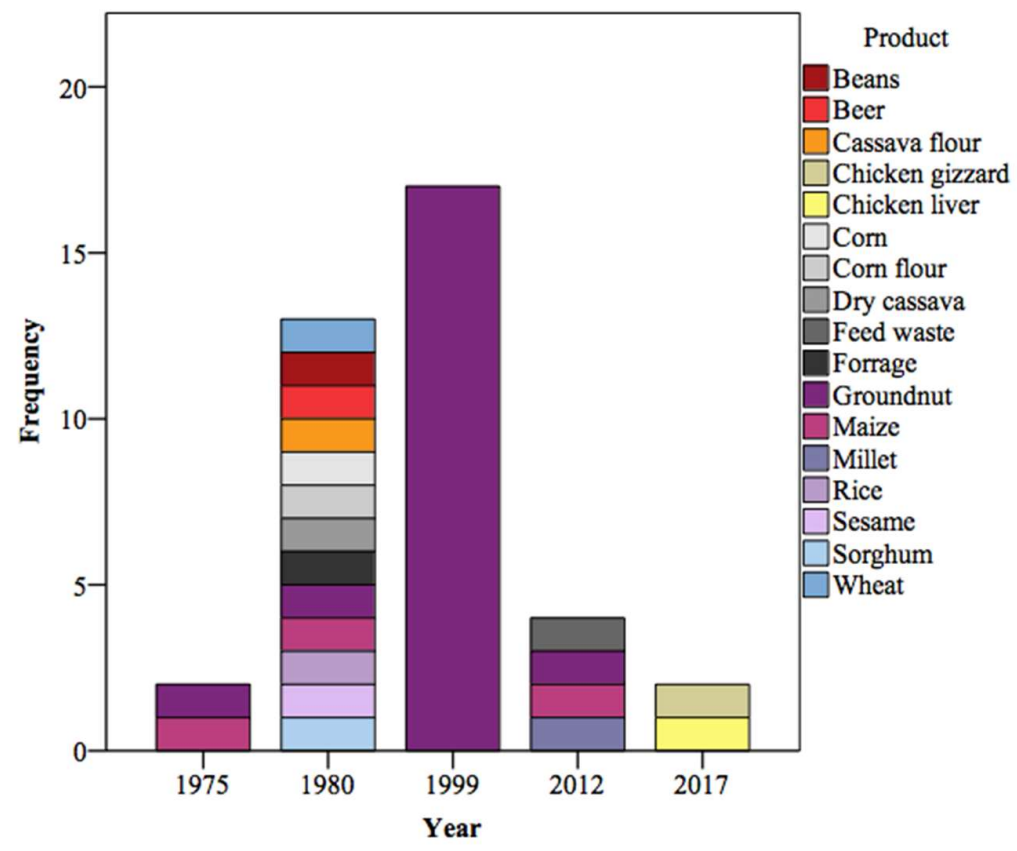

Figure 1. Volume of major aflatoxin research in Mozambique considering the variety of products and frequency of samples.

Groundnuts have always been "on the spotlight", followed by maize. These were the first crops analyzed and the results were published at the time of the independence. Five years later, there was an inclusion of several foods, probably to know which other deserved attention. In the following two 
decades, the focus was exclusively turned to groundnuts, in an unprecedented level of research. Recently, other commodities have been added. These include feed and animal products.

\section{Early studies: biomedical research}

Aflatoxins shall be assumed as a burden since pre-historic times and as a public health issue since the dawn of civilization. Mushroom and mold poisoning are also not a novelty. However, many authors regard the turkey $X$ disease episode [11] as the kick-start of mycotoxin research. According to Homei and Worboys [12]. Brazilian feed caused the death of over 100.000 turkeys in England. It was later found to result from contamination by $\mathrm{AFB}_{1}$ [13]. The fear of such kind of incidents originated a worldwide cascade of intense research as well as policymaking to ensure food and feed safety. Now mycotoxin studies are a well-established multidisciplinary body of knowledge combining contributions from medical, agricultural, legal and other disciplines.

An early record of aflatoxins in Mozambique was published by Mota and Lourenço [14] in Agronomia Moçambicana. They found the $\mathrm{AFB}_{1}$ in cassava in levels exceeding the limits admissible for human consumption. However, it was an isolated study focused on the nutritional and microbiological features, rather than toxicological. Thus, there was little following in such direction. One worth mentioning is Essers and Nout [15] who still believed samples were contaminated, even after failing to detect. They based their conclusion in previous records, a flaw in their method previously explained by Coker and Tomlins [16], and probably their impression by seeing the level of mold infestation. Yet, there was no much interest in aflatoxins because they were actually looking for cyanogenic glycosides. The aflatoxin analysis in cassava seems marginal, performed just because opportunities rise. If there are evidences and eventually resources, this matter should receive more attention.

Groopman, et al. [17] mentioned studies on cancers and their etiologies for the period 1968-1974 in Inhambane. This was certainly the first time interest in aflatoxins has truly risen in Mozambique. Discoveries by Purchase and Goncalves [18] were a for the following two decades of research. They found aflatoxins in foods from cancer patients and mentioned groundnuts as a major source. Van Rensburg, Kirsipuu, Coutinho and Van Der Watt [5] gave continuity and their observations were presented in the following year as strong epidemiological evidence of association between HCC and aflatoxins in the USNR Conference on Mycotoxins in Human and Animal Health [19]. At that time, Kew, et al. [20] described HCC as the most frequent cancer in the south of Mozambique. In 1979-80, the National Institute for Agricultural Research (INIA, now IIAM) surveyed aflatoxins in 17 foods [21,22]. Most samples were contaminated, especially the grains. Later. Van Rensburg, Cook-Mozaffari, Van Schalkwyk, Van der Watt, Vincent and Purchase [1] published a very influential paper on aflatoxins demonstrating their combined impact with HBV in the onset of HCC.

Later, the dietary aflatoxin intake was found to be associated with a codon 249 mutation of the p53 gene in an endemic form of HCC [23]. However, Unsal, et al. [24] demonstrated that HBV also has a major role in the wild-type p53 function, and this mutation seems rare outside Mozambique, even in other places with high incidence of HCC and aflatoxin contaminated food. Sarmento, et al. [25] carried out a relevant following in this line of research, analyzing microsatellite instability in HCC among Portuguese and Mozambican subjects. However, his focus was only cancer, not exploring in depth the relationship between it and aflatoxins HBV or any other possible cause. Yet, he mentioned the toxins among the most probable causes of the differences between the both populations analyzed.

These studies were very enlightening and they still have a lot of potential in three major directions: the aflatoxins in food, the hepatitis and liver cancer. Each can be developed into a wide research topic in Mozambique. Even the work already done can simply be updated, reproduced in different areas. The new molecular and immunological approaches, and information technologies can be a good asset.

Two remarks before moving forward: beware of biases because of the timeframe and misleading secondary sources. 
It is important to consider the timeframe because the mycotoxin research and policymaking outside Mozambique has advanced substantially. For example, investigators such as Mota and Lourenço [14] describe their samples as unacceptable for human consumption, but that seem subjective or even arbitrary by today's standards. By that time, there was no national legislation or international agreement on what should be considered accepted. IARC [26] only published its evaluation of aflatoxins over two decades later, and the Codex Alimentarius Commission [27] issued its Standard for Contaminants and Toxins much later. Yet, these opinions on the acceptability can be accounted as professional subjective observations.

There are many misleading secondary sources in the literature. Most information above is taken directly from the original articles. Some of them are gaining a legacy status but no longer reflecting the current situation. Many publications use the information as recent by lack of deep research, especially now with an abundance of secondary sources not mentioning or emphasizing when the events took part. It is worsen by the culture of "copy-paste". These studies are turning into "cheat-chat", content fillers for dissertations or other academic documents to demonstrate awareness on the subject. This is one of the reasons why this historical review was made. Readers are recommended to double-check the information and search for primary sources when possible.

\section{Recent studies: trade affairs}

In Mozambique, the focus of $\mathrm{AFB}_{1}$ research shifted from studies on hepatic carcinoma to agricultural concerns. This was due to international trade restrictions, specially regarding groundnuts [2,28]. A study by van Wyk, et al. [29] is a pioneer in this direction. According to them, it all started when European countries started to block the entrance of AFB 1 contaminated groundnuts from South African companies supplied by farmers from Nampula province in Mozambique. When they investigated the products found $\mathrm{AFB}_{1}$ levels extremely high.

A major aflatoxicosis outbreak [30] in Kenya also explains the increased concern about AFB1. There had been similar incidents in India [31] and Malaysia [32], but the one in Kenya drew more overall attention and media coverage, probably because of today's efficient information technologies and the higher number of confirmed deaths. estimated to more than 125 by the Centers for Disease Control and Prevention [33]. After this. a group of experts reunited in the World Health Organization's headquarter to develop public health strategies to prevent or control future outbreaks [34]. This is a major concern to Mozambique because both countries have $\mathrm{AFB}_{1}$ a major grain contaminant and share several natural and socio-demographic features.

Mondlane, et al. [35] started by screening for Aspergillus infestation and AFB 1 contamination and relate both in feed for poultry, using samples from four companies. It was an ensemble effort from the University Eduardo Mondlane, Ministry of Health and the Mozambican Institute for Agricultural Research. Most samples were had A. flavus and showed aflatoxin levels above the limits recommended by the Codex Alimentarius. The infested samples had significantly higher toxin levels ( $p=0.003$ ), though some non-infested samples also had $\mathrm{AFB}_{1}$ in minor quantities. It is reasonable, as the industrial treatment probably eliminated partially the molds but not the toxin. Indeed, Carlson and Ensley [36] do not recommend fungal infestation as a predictor of mycotoxin contamination. Nevertheless, the research was an asset for the companies and farmers in general.

A remarkable development for the following years was the introduction of an Aspergillus bio-controller [37,38]. The International Institute of Tropical Agriculture (IITA) developed this product and brought it to Mozambique in collaboration with Eduardo Mondlane University and Lúrio University, and financial support of the United States Department of Agriculture (USDA) [38]. Cardwell, et al. [39] claim this product to be responsible for the aflatoxin reduction in maize and groundnut by 80 to $90 \%$ in Nigeria. They say it was also successful in Kenya. It is now been sold in Nampula province of Mozambique, where IITA has an office.

Augusto, Atehnkeng, Akello, Cotty and Bandyopadhyay [2] studied the prevalence and distribution of Aspergillus in soil samples, and aflatoxin contamination in maize and groundnuts. It covered areas from Nampula, Zambézia, Tete and Manica provinces. The first two showed more abundance of molds and the highest levels of contamination. This study confirmed Nampula as an 
"aflatoxin hot spot" area. AFB 1 in Mozambique major cash crops and expanded the studies to three new provinces. Furthermore, it raised the awareness about the high levels in Zambézia. Two years later, Zuza, et al. [40] published another study of $\mathrm{AFB}_{1}$ in groundnuts from Nampula. However, this group wanted to know how the harvesting time affected the toxin levels. According to them, the farmers have to harvest at the exact time of physiological maturity. They believe a delay results in invasion of the pods by insects and the holes allow the mold's entry. This recommendation was important, not only for the safety but also for the groundnut's quality.

At the same time, Anjos, et al. [41] were also concerned about the exposure, and how to minimize it. However, they explored a completely different perspective and context: there had been studies on how adsorbents can reduce the toxic effects of aflatoxins [42,43]. Thus, the focused on bentonite clay and diatomaceous earth, and tried to see how they would affect the health of chicks. Only bentonite clay showed efficacy, though only moderate. This result was promising because the adsorbent is abundant in Mozambique.

Sineque, et al. [44] also drew their attention to poultry, screening chicken livers and gizzards for $\mathrm{AFB}_{1}$. The samples were from small and industrial abattoirs of Maputo. There were more aflatoxins in livers than gizzards, and the values were not above the limits recommended by the Codex Alimentarius. There is no apparent reason why gizzard should have high aflatoxin level, as the food only passes through. Regarding the liver, one of its functions is exactly to destroy hazardous chemicals [45], so it naturally reduces the quantity of such substances. Yet, it is the organ where these substances accumulate for the same reason. Thus, any amount of toxin should be expected from a chicken after eating contaminated feed. The initiative was good and unique for exploring animal food, and relevant as liver and gizzard are widely eaten as a delicacy in Mozambique.

It is also important to admit the existence of many unpublished works, made for particular consultancy purposes. It is very frequent in Mozambique. Furthermore, many students make resourceful works as part of their education but the information is archived once they finish, and it never "sees the light of day", and many laboratories performed analyses by demand or routine but the results are never explored academically. Thus, there are huge volumes of unexplored databases in Mozambique. They could bring answers and certainly fill some gaps in the current knowledge on the country's aflatoxin research.

These studies certainly give some insight on the country's current situation, but much more is required to draw the "full picture". All authors mention the need to further investigations because their studies are too limited to be conclusive. Each had particular features, probably depending on opportunities and intentions, but the combined contribution show how much is known about AFB 1 in Mozambique and the direction to follow. The research is marginal if compared with the body of material produced in other regions, but most studies here mentioned are pioneers in their own right. The next generations of researchers shall see this as an opportunity to lead in this matter.

\section{Perspectives}

The researchers unanimously agreed there is a need for further research on aflatoxin contamination in Mozambique. Some recommended studies about the incidence and extent of contamination, some point specific commodities such as groundnuts, maize, poultry giblets, milk or others, some talk about the methods for research, improvement of the food, or to reduce the exposure, some about the regularity of the analysis, and some do not specify the path to take. In the end, whichever the direction is, any research on aflatoxin is a step forward.

Aflatoxin studies are multidisciplinary, including biomedical, chemical, agricultural, social, legal and several other components. Mozambique is full of potential from any of these fields and they will sooner or later be addressed. In areas such as Maputo, Inhambane, specially Nampula and possibly Manica, there will be short to mid-term progress regarding aflatoxin control because they have been drawing attention from researchers and the local authorities. However, the six remaining provinces will probably take much longer unless they catch up with the others. 


\section{Final remarks}

Four major forces drove the aflatoxin research in Mozambique: cancer studies, international trade demands, academic will and opportunities. The first two are practical and were necessary at least at some point in time. The academic will has to rely on the former to get support and that is what creates a few unrelated events of intense research. The opportunities frequently come from foreign investment or request for commercial purposes, rarely going beyond that. Some of the best studies do not even involve Mozambican scholars, professionals or institutions. Furthermore, most papers on aflatoxins in Mozambique are either for conferences or one-time studies rather than part of control campaigns, though recently the overall interest in food safety has been rising.

Mozambique is among the countries most affected by $\mathrm{AFB}_{1}$, both in health and economy, and this should be a reason for the country to lead in this line of research. There are now more facilities than ever before, though screening studies require sophisticated and onerous material. Furthermore, there are alternatives to chemical analysis, probably more feasible yet as relevant. Why not, for example, trying search for ways to control known aflatoxigenic Aspergillus strains? Or just to analyze its growth pattern or how the environmental factors affect the mold? Which other crops than groundnuts, maize and cassava are being affected? Why not to perform studies on economic losses? There is no need for much money in order to expand the knowledge about aflatoxin in Mozambique. Different sectors could try to study the best way to address this issue.

The aflatoxin research requires two more forces to truly flourish: the general public concern and the local market's interest. It is necessary to create awareness through mainstream education and media. Aflatoxin-related disorders should be as known as other foodborne diseases. They are endemic in Mozambique and they will not decrease in prevalence unless there is some intervention. Regarding the market, Mozambique much better prepared to meet the international requirements if the local policies are also demanding. It might be difficult to implement in the beginning but high quality products will also encourage international partners to purchase more from Mozambique. The local traders will keep selling low quality products if the clients do not mind buying them as they are. And the clients will never change their behavior without awareness.

One shall praise the effort so far in the Mozambican aflatoxin research and the achievements. The researchers have done much regarding their very limited resources. Yet, there are many challenges still to come, especially regarding the way the different actors will have to participate in the control of aflatoxins. Above all, it will be virtually impossible to do anything if the aflatoxin research does not advance substantially.

Author Contributions: Writing-Original Draft Preparation, Edgar Cambaza; Supervision, Shigenobu Koseki; Supervision, Shuso Kawamura.

Funding: This research received no external funding.

Conflicts of Interest: The authors declare no conflict of interest.

\section{References}

1. Van Rensburg, S.J.; Cook-Mozaffari, P.; Van Schalkwyk, D.J.; Van der Watt, J.J.; Vincent, T.J.; Purchase, I.F. Hepatocellular carcinoma and dietary aflatoxin in mozambique and transkei. Br J Cancer 1985, 51, 713-726.

2. Augusto, J.; Atehnkeng, J.; Akello, J.; Cotty, P.; Bandyopadhyay, R. Prevalence and distribution of aspergillus section flavi in maize and groundnut fields and aflatoxin contamination in mozambique. In 2014 APS-CPS Joint Meeting, The American Phytopathological Society: Minneapolis, Minnesota, 2014.

3. Doko, M.B.; Canet, C.; Brown, N.; Sydenham, E.W.; Mpuchane, S.; Siame, B.A. Natural co-occurrence of fumonisins and zearalenone in cereals and cereal-based foods from eastern and southern africa. Journal of Agricultural and Food Chemistry 1996, 44, 3240-3243. 
4. Warth, B.; Parich, A.; Atehnkeng, J.; Bandyopadhyay, R.; Schuhmacher, R.; Sulyok, M.; Krska, R. Quantitation of mycotoxins in food and feed from burkina faso and mozambique using a modern lc-ms/ms multitoxin method. Journal of agricultural and food chemistry 2012, 60, 9352-9363.

5. Van Rensburg, S.J.; Kirsipuu, A.; Coutinho, L.P.; Van Der Watt, J.J. Circumstances associated with the contamination of food by aflatoxin in a high primary liver cancer area. S Afr Med J 1975, 49, 877-883.

6. Harington, J.S.; McGlashan, N.D.; Bradshaw, E.; Geddes, E.W.; Purves, L.R. A spatial and temporal analysis of four cancers in african gold miners from southern africa. Br J Cancer 1975, 31, 665-678.

7. Habib, A.; Padayachee, V. Economic policy and power relations in south africa's transition to democracy. World Development 2000, 28, 245-263.

8. Sachs, J.D.; McArthur, J.W. The millennium project: A plan for meeting the millennium development goals. The Lancet 2005, 365, 347-353.

9. Conselho de Ministros. Plano de acção para a redução da pobreza absoluta; Conselho de Ministros: Maputo, 2006.

10. Griggs, D.; Stafford-Smith, M.; Gaffney, O.; Rockström, J.; Öhman, M.C.; Shyamsundar, P.; Steffen, W.; Glaser, G.; Kanie, N.; Noble, I. Policy: Sustainable development goals for people and planet. Nature 2013, 495, 305.

11. Stevens, A.; Saunders, C.; Spence, J.; Newham, A. Investigations into" diseases" of turkey poults. Vet. $\operatorname{Rec} 1960,72,627-628$.

12. Homei, A.; Worboys, M. Fungal disease in britain and the united states 1850-2000: Mycoses and modernity. Basingstoke (UK), 2013.

13. Van Der Zijden, A.S.M.; Koelensmid, W.A.A.B.; Boldingh, J.; Barrett, C.B.; Ord, W.O.; Philp, J. Aspergillus flavus and turkey $\mathrm{x}$ disease: Isolation in crystalline form of a toxin responsible for turkey $\mathrm{x}$ disease. Nature 1962, 195, 1060.

14. Mota, T.P.; Lourenço, M.C. A farinha de mandioca de moçambique. Agronomia Mocambicana 1974, 8, 47-59.

15. Essers, A.A.; Nout, M.R. The safety of dark, moulded cassava flour compared with white-a comparison of traditionally dried cassava pieces in north-east mozambique. Journal of Food Technology in Africa 2000, 5, 19-21.

16. Coker, R.D.; Tomlins, K.I. Estimating aflatoxin levels in cassava: New technique developed by tdri. Cassava Newsl 1986, 10, 1-4.

17. Groopman, J.D.; Wang, J.S.; Scholl, P. Molecular biomarkers for aflatoxins: From adducts to gene mutations to human liver cancer. Can J Physiol Pharmacol 1996, 74, 203-209.

18. Purchase, I.; Goncalves, T. In Preliminary results from food analyses in the inhambane area, Symposium on mycotoxins in human health, 1971; Springer: pp 263-269.

19. Van Rensburg, S.J. In The role of epidemiology in the elucidation of mycotoxin health risks, Proceedings of the USNR Conference on Mycotoxins in Human and Animal Health, Maryland, 1977, 1976; Maryland.

20. Kew, M.C.; Marcus, R.; Geddes, E.W. Some characteristics of mozambican-shangaans with primary hepatocellular cancer. South African Medical Journal 1977, 51, 306-309.

21. Casadei, E. Os contaminantes nos alimentos. In Mocambique: Águas, alimentos e ambiente, Molisv: 1980.

22. Baquete, E.; Freire, M. Present status and perspectives of aflatoxin research in mozambique. Aflatoxin Contamination of Groundnut 1989, 93.

23. Ozturk, M. P53 mutation in hepatocellular carcinoma after aflatoxin exposure. Lancet 1991, 338, 1356-1359. 
24. Unsal, H.; Yakicier, C.; Marcais, C.; Kew, M.; Volkmann, M.; Zentgraf, H.; Isselbacher, K.J.; Ozturk, M. Genetic heterogeneity of hepatocellular carcinoma. Proceedings of the National Academy of Sciences of the United States of America 1994, 91, 822-826.

25. Sarmento, J.A.; Ferro, J.; Santos, C.; Seruca, R.; Carneiro, F. Microsatellite instability in hepatocellular carcinomas from two different geographic regions (portugal and mozambique). The American Journal of Gastroenterology 2003, 98, S98.

26. IARC. Aflatoxins. IARC Monographs on the Evaluation of Carcinogenic Risks to Humans 2002, 82, 171-300.

27. Codex Alimentarius Commission. Codex general standard for contaminants and toxins in food and feed. Codex stan 193, 1995. 2013.

28. Harmsen, J.; Bremmer, J.; Maria, R.M. Pre evaluation of a soil and plant laboratory in mozambique; Alterra: Wageningen, 2012; p 60.

29. van Wyk, P.; Van der Merwe, P.; Subrahmanyam, P.; Boughton, D. Aflatoxin contamination of groundnuts in mozambique. International Arachis Newsletter 1999, 19, 25-27.

30. Lewis, L.; Onsongo, M.; Njapau, H.; Schurz-Rogers, H.; Luber, G.; Kieszak, S.; Nyamongo, J.; Backer, L.; Dahiye, A.M.; Misore, A. Aflatoxin contamination of commercial maize products during an outbreak of acute aflatoxicosis in eastern and central kenya. Environmental health perspectives 2005, 113, 1763.

31. Krishnamachari, K.; Nagarajan, V.; Bhat, R.; Tilak, T. Hepatitis due to aflatoxicosis: An outbreak in western india. The Lancet 1975, 305, 1061-1063.

32. Chao, T.C.; Maxwell, S.M.; Wong, S.Y. An outbreak of aflatoxicosis and boric acid poisoning in malaysia: A clinicopathological study. The Journal of pathology 1991, 164, 225-233.

33. Centers for Disease Control and Prevention. Outbreak of aflatoxin poisoning--eastern and central provinces, kenya, january-july 2004. MMWR Morb Mortal Wkly Rep 2004, 53, 790-793.

34. Strosnider, H.; Azziz-Baumgartner, E.; Banziger, M.; Bhat, R.V.; Breiman, R.; Brune, M.N.; DeCock, K.; Dilley, A.; Groopman, J.; Hell, K., et al. Workgroup report: Public health strategies for reducing aflatoxin exposure in developing countries. Environ Health Perspect 2006, 114, 1898-1903.

35. Mondlane, I.A.P.; Capece, B.P.S.; Parruque, A.F. Relação entre a ocorrência de fungos e a presença de aflatoxinas b1 em rações para aves fabricadas em maputo; Instituto de Investigação Agrária de Moçambique: Maputo, 2005.

36. Carlson, M.P.; Ensley, S.M. Sampling and analyzing feed for fungal (mold) toxins (mycotoxins). Cooperative Extension, Institute of Agriculture and Natural Resources, University of Nebraska-Lincoln: 2003.

37. U.S. Embassy Maputo. Inauguration of iita's new facilities in the celebration of its 50th year anniversary.

https://mz.usembassy.gov/inauguration-iitas-new-facilities-celebration-50th-year-an niversary/

38. Bandyopadhyay, R.; Dubois, T. Aflatoxin control projects launched in southern africa. IIAPPS Newsletter 2012, 2.

39. Cardwell, K.; Cotty, P.; Bandyopadhyay, R.; Mutegi, C.; Nelson, F.; Marwa, M.; Manyong, V. Biocontrol for aflatoxin; International Institute for Tropical Agriculture (IITA): Dar es Salaam, 2015; p 50.

40. Zuza, E.; Mondjana, A.; Muitia, A.; Amane, M. Effects of harvesting date on aflatoxin contamination in groundnuts in northern mozambique. In The Fifth RUFORUM Biennial Conference and African Higher Education Week, Nampala, M.P.; Egeru, A.; Tusiime, G.; Osiru, M.; Mensah, S.; Adipala, E., Eds. 
Regional Universities Forum for Capacity Building in Agriculture (RUFORUM): Cape Town, 2016; Vol. 14, pp 167-172.

41. Anjos, F.D.; Ledoux, D.; Rottinghaus, G.; Chimonyo, M. Efficacy of mozambican bentonite and diatomaceous earth in reducing the toxic effects of aflatoxins in chicks. World Mycotoxin Journal 2016, 9 , 63-72.

42. Modirsanei, M.; Mansoori, B.; Khosravi, A.R.; Kiaei, M.M.; Khazraeinia, P.; Farkhoy, M.; Masoumi, Z. Effect of diatomaceous earth on the performance and blood variables of broiler chicks during experimental aflatoxicosis. Journal of the Science of Food and Agriculture 2008, 88, 626-632.

43. Huwig, A.; Freimund, S.; Käppeli, O.; Dutler, H. Mycotoxin detoxication of animal feed by different adsorbents. Toxicology letters 2001, 122, 179-188.

44. Sineque, A.R.; Macuamule, C.L.; Dos Anjos, F.R. Aflatoxin b1 contamination in chicken livers and gizzards from industrial and small abattoirs, measured by elisa technique in maputo, mozambique. Int J Environ Res Public Health 2017, 14.

45. Rouiller, C. The liver: Morphology, biochemistry, physiology. Academic Press: 2013. 